\title{
O zoneamento ecológico-econômico e a multiplicidade de ordens socioambientais na Amazônia
}

\section{Henri Acselrad}

Professor do Instituto de Pesquisa e Planejamento Urbano e Regional da Universidade Federal do Rio de Janeiro (IPPUR/UFRJ) e pesquisador do CNPq.

\section{Resumo}

A consideração da variável ambiental tem alterado as dinâmicas correntes do planejamento territorial. O desenvolvimento de uma sociologia do planejamento territorial seria de grande valia para entendermos melhor os caminhos e os descaminhos dessa "ambientalização" do planejamento. O zoneamento ecológico-econômico (ZEE) é um objeto particularmente fértil para a produção de tal conhecimento. Este artigo é um reflexão sobre os métodos do ZEE, caracterizando seus impasses e os conflitos que necessariamente os envolvem. O objetivo é ajudar a fazer do zoneamento um instrumento real de mudança nas dinâmicas socioterritoriais hoje prevalecentes na Amazônia.

\section{Palavras-Chave}

Amazônia - Zoneamento Econômico Ecológico - Sociologia do Planejamento

\section{Abstract}

The consideration of the environmental variable has been changed the present dynamics of the territorial planning. The development of a sociology of the territorial planning would be worthwhile for us to better understand the paths of that "environmentalizing" of the planning. The EcologicalEconomical Zoning (EEY) is a particularly fertile object for producting of such knowledge. This article is a reflection on the methods of $\mathrm{ZEE}$, characterizing its impasses and the conflicts that necessarily involve them. The objective is to help to do the zoning a real change instrument acting in the social-territorial dynamics prevalent in the Amazonian

\section{Keywords}

Amazonian - Ecological-Economical Zoning - Sociology of the Planing 


\section{Introdução}

A consideração da variável ambiental tem, por diferentes caminhos, alterado as dinâmicas correntes do planejamento territorial. A incorporação dessa variável às concepções e práticas de planejamento é imposta por múltiplas forças e contextos sociais. O desenvolvimento de uma sociologia do planejamento territorial seria de grande valia para entendermos melhor os caminhos e os descaminhos da "ambientalização" do planejamento. O Zoneamento Ecológico-Econômico (ZEE) é um objeto particularmente fértil para a produção de tal conhecimento, para cuja elaboração inicial pretende contribuir o presente texto.

Qualquer consulta que se faça à produção documental sobre o ZEE e aos textos aplicados à região amazônica, em particular, faz saltar aos olhos a referência constante a suas "dificuldades metodológicas". Ante a complexidade das dinâmicas socioterritoriais encontradas, afirma-se recorrentemente uma angústia anticartesiana e uma pretensão holística, a busca de indicadores que exprimam a associação apropriada entre variáveis sociais e geofisiográficas, e, por fim, o desencanto com a falta de "sustentabilidade política" do ZEE, dada a inconformidade da realidade social em face dos propósitos e marcos conceituais que orientam a implementação desse instrumento do planejamento territorial. Pensamos poder afirmar que essas dificuldades e angústias estariam refletindo aquilo que De Certeau chamou "um enorme resto feito de sistemas culturais múltiplos e fluidos, situados entre as maneiras de se utilizar o espaço e o planejamento", que geram "um fluxo de murmúrios nas regiões avançadas do planejamento"1. E as mencionadas dificuldades metodológicas, por sua vez, seriam a expressão mesma da tensão entre o espaço geometrizado, estático e relativamente homogêneo da idealização zoneadora e o território usado, nos termos de Milton Santos, enquanto "forma-conteúdo em processo de mudança"2.

Em comunicação ao seminário sobre ZEE organizado pelo Ministério do Meio Ambiente em outubro de 2000 em Manaus, afirmava um representante do Banco Mundial:

"A sociedade é caracterizada por conflitos, muitas vezes sobre o uso da terra e seus recursos. A resolução de conflitos sociais se dá através do processo político. O processo técnico de planejamento tem certa tendência de esperar que ele, por si só, possa levar a um consenso, a uma harmonia social sobre o assunto. Certamente pode contri-

${ }^{1}$ Cf. Michel de Certeau. A Cultura no Plural. São Paulo: Papirus, 1995, p. 234.

${ }^{2}$ Cf. Milton Santos. O Território e o Saber Local: algumas categorias de análise. Cadernos IPPUR, v. XIII, n. 2, ago.-dez. 1999, p. 18. 
buir para tal. Mas o zoneamento não deve ignorar a existência de conflitos de interesses como um fato básico social, e terá mais chances de sucesso se for conduzido como um processo de negociação, de resolução de conflitos entre os 'stakeholders'. Parece, inclusive, que deveria começar logo com o diálogo entre os stakeholders sobre os problemas e opções por eles percebidos, e não com as pesquisas e os mapas" ${ }^{\prime \prime}$.

Ora, a decisão de se repensar as metodologias do ZEE, afirmada a partir de meados do ano 2000 por instâncias do Ministério do Meio Ambiente, do Banco Mundial e de setores da academia, exprime, por certo, a vontade de se "ouvir o fluxo de murmúrios" descrito por De Certeau, de tornar visíveis e trabalháveis esses "restos culturais situados entre o espaço usado e o planejamento". Refletir sobre os métodos do ZEE, caracterizando seus impasses e os conflitos que necessariamente os envolvem, constitui um esforço que poderá ajudar substancialmente a fazer do zoneamento um instrumento real de mudança nas dinâmicas socioterritoriais hoje prevalecentes na Amazônia.

\section{O ZEE como representação ordenada do território}

A literatura que trata da relação entre a cartografia e os sistemas de poder mostra que os mapas carregam não só um conjunto de signos e imagens retóricas, mas também os imperativos territoriais dos sistemas políticos. Cabe, portanto, aos analistas saber fazê-los dizer aquilo que eles apenas sugerem, ou, por vezes, encobrem. Ora, no caso do ZEE, ao contrário, tratam-se de "mapas falantes" por si mesmos, que se apresentam não como reflexos passivos do mundo dos objetos, mas como intérpretes do que alguns pretendem que seja "a verdade ecológica deste mundo". Explicitamente, os mapas do ZEE "ordenam e dão ordens". Seus enunciados são mais performáticos do que constatativos ${ }^{4}$. Pois a cartografia no ZEE contém uma dupla temporalidade - a da história demarcada espacialmente por meio de signos selecionados e a do futuro imaginado, representando as coisas como tensão na qual o lugar geográfico é, ao mesmo tempo, um horizonte. Mas se, ao contrário dos mapas correntes que se pretendem reflexos neutros do real, a cartografia no ZEE é explicitamente "performática" e "falante", caberá analisar os diferentes conteúdos e tensões embutidos nessas "falas", em sua dimensão tanto "representacional" como "prescritiva".

${ }^{3}$ Cf. Christoph Diewald. ZEE - Como continuar? In: SEMINÁRIO SOBRE ZONEAMENTO ECOLÓGICO ECONÔMICO, 2000, Manaus. Anais... Manaus: MMA, 2000, p. 3.

${ }^{4}$ Cf. J. Loup Rivière. La Carte et la Décision. In: Cartes et Figures de la Terre. Paris: CCI/Centre Georges Pompidou, 1980, p. 379. 
Inicialmente, cabe destacar que o imaginário cartográfico e as representações do território para fins de zoneamento procuram fragmentar o real para melhor defini-lo, descrevê-lo e, em definitivo, orientar sua apropriação ${ }^{5}$. A fragmentação do espaço resulta assim da vontade de ajustar cada uma de suas porções a um determinado tipo de projeto. Esse ajuste será entendido, por vezes, como um encontro com a "verdade do lugar"6, verdade disseminada e encontrável no mundo das coisas. No entanto, a representação cartográfica do ZEE é portadora de um conjunto de crenças que redescrevem o mundo, traduzindo um regime específico de verdade ${ }^{7}$. Pois, por trás dessa pretensa verdade ecológica do território, estar-se-á, de fato, tomando o espaço representado por uma "cópia idêntica de algo cujo original jamais existiu"8 . Conseqüentemente, a busca da "verdade ecológica" das coisas não evita que, via de regra, a ilusão da ordem almejada seja desfeita antes mesmo de se realizar - os dados serão considerados inatuais, as zonas idealizadas mostrar-se-ão incompatíveis com as realidades sociais do terreno, as políticas fundiárias federais desautorizarão as destinações de área feitas por órgãos estaduais etc. A dinâmica social negará assim, repetidamente, esses estados estáveis e definitivos das representações, das quais se tende, com freqüência, a subtrair a própria História.

\section{O ZEE como totalização e o fim da fronteira (ou como conhecer as coisas para o mercado)}

Ora, o ZEE é visto correntemente como um instrumento ao mesmo tempo técnico e político ${ }^{9}$. Mas os diferentes discursos sobre as metodologias do ZEE carregam ambigüidades internas, expressivas de sua pretensa duplicidade de caráter. O ZEE poderá significar, ao mesmo tempo, um meio de identificação técnica de "fatos ambientais", vistos separadamente das chamadas "características antrópicas" da ocupação, ou, alternativamente, "um diagnóstico de situações ecossociais em transformação". Poderá ser entendido ora como instrumento da identificação das "vocações naturais das células espaciais", ora como meio "de caracterização de zonas equiproblemáticas para processos de negociação e regulação jurídico-política".

\footnotetext{
Cf. F. Lestringant. Insulaire. In: Cartes et Figures de la Terre, p. 470, apud Pierre Jourde, op. cit., p. 122.

${ }^{6}$ Na perspectiva de alguns técnicos do ZEE, a identificação das unidades ambientais e da ecodinâmica levaria à caracterização da "verdade terrestre". Cf. Audiência Pública, Proposta de Fiscalização e Controle, Brasília, 18/10/1995, p. 13.

Cf. G. Balandier, Images, Images, Images. Cahiers Internationaux de Sociologie, v. LXXXIII, juin 1987, PUF.

Cf. F. Jameson. Pós-Modernismo: a lógica cultural do capitalismo tardio. Ed. Ática, 1996, p. 4.

Cf. H. Schubart. O Zoneamento Ecológico-Econômico e o Ordenamento Territorial: Aspectos jurídicos, administrativos e institucionais. In: WORKSHOP ZONEAMENTO ECOLÓGICO-ECONÔMICO: INSTRUMENTO PARA O DESENVOLVIMENTO SUSTENTÁVEL DOS RECURSOS DA AMAZÔNIA, 1994, Manaus. Anais... Manaus: Instituto Nacional de Pesquisa da Amazônia, 1994.
} 
Os princípios metodológicos presentes nos diferentes documentos técnicos apresentam assim as ambigüidades internas relativas à pretensão, por um lado, de se produzir um conhecimento objetivo sobre "as realidades físicas e sociais do território", em que "potencialidades e vulnerabilidades" são determinadas sem nenhuma remissão aos sujeitos da avaliação, e, por outro lado, de se reconhecer que o ZEE consiste em um diagnóstico de processos históricos territorializados, expresso na caracterização de zonas "equiproblemáticas", a partir de pontos de vista cuja legitimidade deve, portanto, ser construída e evidenciada.

É difícil, assim, não assinalar que o chamado "componente especificamente técnico" do ZEE encerra já claramente elementos de um projeto político: o do "encontro técnico" do país consigo mesmo, a realização do que seria a "potência" suposta do território. As contradições evidenciadas pela experiência do ZEE na Amazônia mostram-nos que, se considerarmos os três momentos de sua realização - a pré-compreensão do mundo da ação, a configuração do ordenamento proposto e a mediação social -, o campo de intervenção política não se limita ao momento da decisão final, mas perpassa por todo o processo ${ }^{10}$. Quando o mapeamento começa, um novo locus de negociação e conflito potencial acerca do acesso aos recursos torna-se o centro da cena. O processo de zoneamento desencadeia uma reinterpretação dos direitos aos recur$\operatorname{sos}^{11}$ que termina por se chocar com a idéia de um consenso que se quer fundado na "verdade ecológica do território", desvelada pela força da prática e da imagética classificatória" ${ }^{12}$.

Isto porque o ZEE tende a ser a expressão espacializada de algum "modelo de desenvolvimento", ou seja, de um conjunto de relações sociais territorializadas que exprime uma vontade de futuro. Ou então, em outros termos, um "instrumento de resolução preventiva de conflitos" que arbitra os modos tidos como legítimos de ocupação e apropriação do território.

Nessa ótica, o núcleo central de implementação de um ZEE "reflexivo" e mais ancorado na sociologia complexa do território consiste no trabalho de evidenciar o modelo de desenvolvimento a que o zoneamento se associa ou de cuja construção ele pode constituir um momento. Deve-se ter em mente, assim, quem são os sujeitos do olhar e da

\footnotetext{
${ }^{10}$ Cf. M. Lussault. La Ville Clarifiée. In: L. Cambézy; R. de Maximy (eds.). La Cartographie en Débat. Paris: Karthala/ORSTOM, 1995, p. 172 .

${ }^{11}$ Cf. N. L. Peluso. Whose Woods are these? Counter-mapping Forest Territories in Kalimantan, Indonesia. Antipoide27:4, 1995, p. 388.

12 "A práxis [planejadora], apoiada na imagética", pergunta Lussault, "não está se lançando numa sofística onde o conteúdo da representação importaria menos do que a perfeição de seu registro - fenômeno que a difusão rápida das novas tecnologias, em uma comunidade seduzida pelos instrumentos técnicos, só veio acentuar?" Cf. Michel Lussault. La Ville Clarifiée. In: L. Cambézy; R. de Maximy (eds.). La Cartographie en Débat. Paris: Karthala/ORSTOM, 1995, p. 192.
} 
classificação do território. Ou seja, deve-se tentar identificar o conjunto de forças sociais de sustentação do modelo espacializado de desenvolvimento de cuja costura o ZEE participa.

Ora, os textos estratégicos e metodológicos sobre o ZEE associam, com freqüência, a racionalidade econômico-ecológica à pretensão a uma "apropriação completa do território", à "plena utilização do espaço" e à "plena integração da região ao espaço nacional", assim como ao alcance de "qualidade total no uso do espaço", ao recurso à "abordagem holística que permita considerar a totalidade das oportunidades de uso do espaço e dos recursos naturais", "retratando a realidade com tudo o que nela houver"13 e nela instaurando "uma vigilância total"14. Tratase evidentemente de instaurar uma unidade holística e totalizante, à qual a diversidade social territorializada estaria subordinada. Mas qual seria a lógica dessa totalização? Na metodologia do ZEE de 1997, é perceptível a analogia entre o espaço a planejar e a idéia de empresa: caberia procurar atingir a plena capacidade produtiva do território, "otimizando o uso do espaço" e atribuindo-lhe "eficiência técnica compatível com a competição internacional"15.

Essa pretensão à totalização ora técnico-material, ora mercantil do espaço amazônico não é, porém, sem conseqüências sobre o caráter especificamente diversificado do tecido social da região, caracterizado pela presença da fronteira de expansão do mercado e do capital, fronteira esta que constitui simultaneamente o lugar da alteridade e a expressão da contemporaneidade de tempos históricos e que configura a unidade do diverso ${ }^{16}$. A busca de uma totalização técnico-material do território amazônico seria assim expressão da própria negação da fronteira, a redução da diversidade social à "diferença geográfica", a submissão da alteridade à unidade temporal do mercado mundializado, esta totalidade não dialética que tende a configurar práticas de negação do conflito e anulação simbólica do outro. Essa negação pode dar-se tanto pela redução do outro à condição de pura Natureza - expressa no chamado "molde" pelo qual a terminologia técnica do ZEE propôs-se a considerar certas comunidades como conformes à Natureza ${ }^{17}$ - como pela "promoção" de certos territórios e atores sociais à condição de portadores naturais de uma "potência competitiva". Essa totalidade discursiva vem destruir, portanto, simboli-

\footnotetext{
${ }^{13}$ Cf. Secretaria de Assuntos Estratégicos, Detalhamento da Metodologia do ZEE, Brasília, 1997 e entrevista com técnico do ZEE. ${ }^{14}$ Cf. C. Brigagão. O Caso SIVAM, Inteligência e Marketing. Rio de Janeiro: Ed. Record, 1996, p. 48.

${ }^{15} \mathrm{Cf}$. Secretaria de Assuntos Estratégicos, Detalhamento da Metodologia do ZEE, Brasília, 1997, p. 12.

${ }^{16}$ Cf. J. de S. Martins. O Tempo de Fronteira - retorno à controvérsia sobre o tempo histórico da frente de expansão e da frente pioneira. Tempo Social, 8(1), p. 25-70, maio 1996.

${ }^{17} \mathrm{O}$ "molde" é o termo utilizado pelo professor Aziz Ab'Saber para designar "o somatório dos espaços a serem legal e permanentemente defendidos (reservas indígenas, parques nacionais, reservas florestais, reservas biológicas, estações ecológicas)". Cf. Aziz Ab'Saber. Zoneamento econômico-ecológico. Estudos Avançados, v. 3, nº 5, jan.-abr. 1989, p. 10.
} 
camente, aquela diversidade de situações e tempos históricos que o próprio capital costuma juntar sem destruir. Obscurecidos os conflitos, o território apresentar-se-ia como pura base material para a "inserção competitiva". E os "atores regionais" do desenvolvimento - agora "sustentável" - seriam os puros empreendedores das "vocações" ditadas pelo mercado mundial e interpretadas pelos planejadores.

Nessa ótica, o ZEE poderia ser reduzido à simples dimensão territorial do que tem sido chamado modernização ecológica - "processo pelo qual as instituições políticas internalizam preocupações ecológicas no propósito de conciliar o crescimento econômico com a resolução dos problemas ambientais, dando-se ênfase à adaptação tecnológica, à celebração da economia de mercado, à crença na colaboração e no consenso"18. Ou seja, um simples ajuste ecológico de um modelo que desestabiliza a pequena produção e gera desigualdade social. Esse parece ser o projeto mais compatível com o discurso ambiental prevalecente no Estudo dos Eixos Nacionais de Integração e Desenvolvimento, no qual o meio ambiente foi "descoberto" como "oportunidade de negócios", devendo ser, portanto, internalizado pelo mercado.

O estudo dos Eixos diz pretender recuperar o papel do espaço territorial no planejamento do desenvolvimento, "identificando uma nova geografia sócio-econômica para o Brasil"19 . O espaço considerado é, no entanto, um espaço unidimensional, o espaço dos negócios. Assim, a delimitação dos eixos serve antes de fundamento científico destinado a legitimar as ações e a distribuição espacial dos investimentos. O programa não esconde seu cunho exportador, pois todos os eixos vinculam uma região produtora a um porto, com pouca ação no sentido da integração interna. No que diz respeito ao Eixo do Arco Norte e Madeira Amazonas, por exemplo -, há fundados temores de que se formem dois imensos multimodais de circulação estimulando a produção exportadora de soja a partir do cinturão já existente no cerrado, podendo atingir áreas de florestas, na ausência de medidas que façam essa expansão restringir-se às áreas já degradadas ${ }^{20}$.

Por outro lado, ao direcionarem-se os investimentos para a redução dos estrangulamentos sinalizados pelo mercado, tende-se a concentrar ainda mais as atividades e a renda onde ela já se encontra concentrada. Pois os investimentos privados, pode-se supor, deverão continuar dirigindo-se para onde as externalidades positivas existentes lhes assegurem rentabilidade. Ao se buscar responder aos estrangulamen-

\footnotetext{
${ }^{18}$ Cf. A. Blowers. Environmental Policy: Ecological Modernization or the Risk Society. Urban Studies, v. 34, n. 5-6, 1997, p. 845 .

${ }^{19}$ Cf. Notícias do Brasil, Informativo PPA, MOG, Brasília, 1999, p. 2.

${ }^{20}$ Cf. Bertha Becker. Cenários de Curto Prazo para o Desenvolvimento da Amazônia. LAGET/UFRJ, mimeo. 2000, p.26
} 
tos apontados pelo próprio mercado, abdica-se, em realidade, da implementação de efetivos "projetos estruturantes". O que parece, conseqüentemente, ocupar o centro do planejamento territorial é a vontade de acelerar a velocidade de circulação das mercadorias, substituindo-se as políticas animadas por propósitos redistributivos - sociais e regionais - mediante uma ação governamental facilitadora e market-friendly.

\section{Considerações finais: o ZEE como instrumento de democratiza- ção do desenvolvimento}

No confronto entre diferentes modelos para a Amazônia, não há razão para acreditar ser a integração privilegiada nos fluxos mundializados de comércio o caminho estratégico preferencial e inelutável. Pois, ante as pressões por um ZEE hegemonizado pelo mercado mundial, que reduziria o território aos termos de sua "potência competitiva", é possível pensar-se um ZEE que não totalize nem homogeneíze o território, mas que dialogue com a diversidade social em seus diferentes níveis de articulação e configuração de projetos. O seu objeto não seria, nessa ótica, um território socialmente vazio e estático, mas sim o espaço relacional e complexo de dinâmicas socioterritoriais em processo. Para cumprir, no entanto, esse papel de terreno simbólico da discussão e articulação de um novo modelo de desenvolvimento para a Amazônia, esse "mecanismo de resolução preventiva de conflitos" deverá apoiar-se em critérios de tratamento dos referidos conflitos: ou seja, é preciso deixar clara a escolha entre uma estratégia que reduz o ZEE aos propósitos da economia de recursos naturais e uma outra que o eleve à condição mais ampla de instrumento de construção do que se possa entender por uma justiça ambiental. Assim, esse ZEE "reflexivo", em que os conflitos venham a ser tratados com base em critérios de "justiça ambiental", poderá constituir um momento na construção de um modelo alternativo, que reconheça a pluralidade de tempos e espaços sociais, de territorialidades e regionalidades, saberes e sistemas jurídicos informais de apropriação e uso dos recursos amazônicos. Esse tipo de ZEE poderá tornar-se um fio na trama em que se costuram os pactos sociais de sustentação de modelos alternativos de desenvolvimento. Nele, por certo, o meio ambiente não seria visto nem como mera "oportunidade de negócios", nem como "camisa de força restritiva" do desenvolvimento, mas sim como uma instância de construção territorializada de justiça. Por meio desse zoneamento, estar-se-á pensando um meio ambiente que seja não só do mercado ou mesmo da racionalização dos limites desse mercado, mas também do conjunto dos sujeitos de um desenvolvimento que se quer democraticamente construído.

A pesquisa documental que serviu de base para o presente trabalho contou com a colaboração de Cecília Campello Mello e Maria Nilda Bizzo. 


\section{Referências bibliográficas}

AB'SABER, Aziz. Zoneamento ecológico e econômico da Amazônia: questões de escala e método. Estudos Avançados. São Paulo, v. 3, nº 5 , p.4-20, jan.-abr. 1989.

ACSELRAD, Henri. Experiências regionais. In: SEMINÁRIO DIVERSIDADE ECO-SOCIAL E ESTRATÉGIAS DE COOPERAÇÃO ENTRE ONGS DA AMAZÔNIA, 1994, Belém. Anais... Belém: FAOR-FASE, 1994.

BECKER, Bertha K. Novos rumos da política regional: por um desenvolvimento sustentável da fronteira amazônica. In:SIMPÓSIO INTERNACIONAL O DESAFIO DO DESENVOLVIMENTO SUSTENTÁVEL E A GEOGRAFIA POLÍTICA, 1995, Rio de Janeiro. Resumos expandidos. Rio de Janeiro: UFRJ/IGEO (Departamento de Geografia), 1995.

BIZZO, M. N. S. O Zoneamento Sócio-Econômico-Ecológico de Rondônia. 1999. Dissertação (Mestrado) - IPPUR/UFRJ, Rio de Janeiro, 1999.

CÂMARA DOS DEPUTADOS (Brasil). Proposta de fiscalização e controle $n^{\circ} 11$ (dos Srs. Ivan Valente e Gilney Viana). 1995.

(Brasil).Comissão de Defesa do Consumidor, Meio Ambiente e Minorias. Notas taquigráficas - audiência pública (Tema: esclarecimento sobre o Programa de Zoneamento Ecológico-Econômico). Brasília, 1995.

CCZEE - Zoneamento Ecológico-Econômico. Informe sobre a 19a Reunião Ordinária da Comissão Coordenadora de Zoneamento Ecológico e Econômico do Território Nacional. [s.l., s.d.].

CRUZ, Ana Lúcia da. O Zoneamento Ecológico-Econômico da Amazônia Legal. In: BRASIL. IEA (Instituto de Estudos Amazônicos e Ambientais). Projeto de Políticas Públicas. Brasília, 1993.

FEARNSIDE, Philip M. Desmatamento e desenvolvimento agrícola na Amazônia brasileira. In: LENA, P.; OLIVEIRA, A. E. de (orgs.). Amazônia: a fronteira agrícola 20 anos depois. Belém: Museu Paraense Emilio Goeldi, 1991. 
FERREIRA, Antônia M. M. Contribuição ao debate sobre metodologia aplicada a estudos de Zoneamento Ecológico-Econômico: Projeto Amazônia Legal. In: SEMINÁRIO DIVERSIDADE ECO-SOCIAL E ESTRATÉGIAS DE COOPERAÇÃO ENTRE ONGS DA AMAZÔNIA, 1994, Belém. Anais... Belém: FAOR-FASE, 1994.

IDESP. Zoneamento Ecológico-Econômico da Amazônia: contribuição do IDESP. Belém, 1989.

IBGE. Diagnóstico ambiental da Amazônia Legal: nota técnica. Rio de Janeiro, 1993.

IBGE (Diretoria de Geociências). Metodologia para Zoneamento Ecológico-Econômico na Região Amazônica: contribuição para um debate. Rio de Janeiro, 1993.

LAGET/UFRJ (Laboratório de Gestão do Território) (técnicos responsáveis: Bertha K. Becker e Cláudio A. G. Egler). Detalhamento da Metodologia para Execução do Zoneamento Ecológico-Econômico pelos Estados da Amazônia Legal. SAE/MMA (Secretaria de Assuntos Estratégicos - Ministério do Meio Ambiente), fevereiro de 1996.

MILLIKAN, B. Zoneamento Sócio-Econômico-Ecológico no Estado de Rondônia: análise de um instrumento de ordenamento territorial na fronteira amazônica. Brasília: PNUD/PLANAFLORO, 1998.

NITSCH, Manfred. Riscos do planejamento regional na Amazônia brasileira: observações relativas à lógica complexa do zoneamento. In: D'INCAO, Maria Ângela; SILVEIRA, Isolda Maciel. Amazônia e a crise da modernização. Belém: Museu Paraense Emilio Goeldi, 1994.

Social and Economic implications of recent strategies for Amazonia: a critical assessment. In: INTERNATIONAL WORKSHOP INTERDISCIPLINARY RESEARCH ON THE CONSERVATION AND SUSTAINABLE USE OF THE AMAZONIAN RAIN FOREST AND ITS INFORMATION REQUIREMENTS, 1996, Brasília. Revised paper. Brasília, 1995).

PEDLOWSKI, M. A. An Emerging Partnership in Regional Economic Development: Non-Governmental Organizations, Local State and the World Bank. A Case Study of Planafloro, Rondônia, Brazil. 1998. Tese (Doutorado em Philosophy in Environmental Design and Planning) - Virginia Polytechnic Institute and State University, 1998. 
SAE/FBDS/FUNCATE. Termo de Convênio de Cooperação Técnica entre SAE, FBDS e FUNCATE para a eficácia e execução do Programa de Zoneamento Ecológico-Econômico do Território Nacional. Brasília, 1994.

SAE/PR. As fases e as etapas do Zoneamento Ecológico-Econômico do Território Nacional. Brasília, 1995.

SAE/PR. Zoneamento Ecológico Econômico com prioridade para a Amazônia Legal. Relatório do Grupo de Trabalho instituído pelo Decreto $\mathrm{n}^{\circ}$ 99.246, de 10 de maio de 1990.

SAE/SPF/PR. Zoneamento Ecológico-Econômico: versão a ser apresentada à comissão de coordenação do Programa Piloto para a Proteção das Florestas Tropicais no Brasil. 1993.

SCHUBART, Herbert O. R. O Zoneamento Ecológico-Econômico e o Ordenamento Territorial: Aspectos jurídicos, administrativos e institucionais. In: WORKSHOP ZONEAMENTO ECOLÓGICO-ECONÔMICO: INSTRUMENTO PARA O DESENVOLVIMENTO SUSTENTÁVEL DOS RECURSOS DA AMAZÔNIA, 1994, Manaus. Anais... Manaus: Instituto Nacional de Pesquisa da Amazônia, 1994.

.Planejando a Ocupação Sustentável do Território Nacional: O Exemplo da Amazônia. In: Planejamento de Políticas Públicas. Brasília, IPEA, (7), jun. 1992.

. Zoneamento Ecológico-Econômico da Amazônia. In: FÓRUM NACIONAL COMO EVITAR QUE OS ANOS 90 SEJAM UMA NOVA DÉCADA PERDIDA, IV,. 1991. Rio de Janeiro. Painel Desenvolvimento e Meio Ambiente. Rio de Janeiro: INE (Instituto Nacional de Altos Estudos), 1991.

VIANA JR., Marco Aurélio. O Zoneamento Ecológico-Econômico e a Sociedade Civil. In: SEMINÁRIO DIVERSIDADE ECO-SOCIAL E ESTRATÉGIAS DE COOPERAÇÃO ENTRE ONGS DA AMAZÔNIA, 1994, Belém. Anais... Belém: FAOR-FASE, 1994. 